\title{
Exploratory Study on Online Social Networks User from SASANG Constitution- Focused on Korean Facebook Users
}

\author{
Joung Youn Lee ${ }^{1}$, Hyun Suk Kim ${ }^{2}$, Eun Jung $\mathrm{Choi}^{3}$, and Soon Jung Choi ${ }^{3}$ \\ ${ }^{1}$ Newmedia Department, Korean German Institute of Technology, Korea \\ jylee@kgit.ac.kr \\ ${ }^{2}$ Visual Communication, School of Design, Hong Ik University \\ kylekimegmail.com \\ ${ }^{3}$ Media Design, Korean German Institute of Technology, Korea \\ Choi2joy@gmail.com, soonjung89@naver.com
}

\begin{abstract}
This research seeks to adopt and implement SASANG Constitution to categorize usage of OSNs by a user's physiological type. An online survey (N=102) was conducted on a Facebook page and to identify Facebook users' SASANG Constitution, QSCC II was distributed. All results were collected through email. From the critical literature review, three hypotheses were established, and after a survey the following conclusions were drawn. So-Eum (SE), in comparison to its counterpart So-Yang (SY) who possesses more emotional stability, had less of Facebook usage time and frequency. The introverted SoEum (SE) with high neuroticism placed more meaning on expression of oneself in their usage of the Facebook. The introverted So-Eum with high neuroticism documented their personal information with higher accuracy. This research focused on analyzing OSN usage patterns as seen through user's personality factors. This research was the first attempt in Korea to explore SASANG Constitution and OSN users' Constitution, thus had its innate research limits. Yet, nonetheless, it sheds light into the untapped area of researching a design as seen through OSN user's Constitution.
\end{abstract}

Keywords: SASANG Constitutional Theory, Five Factor Model, Personality, Online Social Networks.

\section{Introduction}

From broadcasting to interpersonal conversations, the modern internet has been presented as a combination of all previous technologies [4]. With these capabilities, the internet has created shift in paradigm of communication practices. One of consequences of the changes is various forms of computer mediated communication (CMC) has become one of major source of social interaction. Because online interactions generate more self-disclosure and fostered deeper personal questions than did face to face $(\mathrm{FtF})$ conversations, $\mathrm{CMC}$ may results in a stronger relationship than might be possible through $\mathrm{FtF}$ methods [11]. 
One of most famous OSNs in Korea, Facebook have users which account for about $18 \%$ of the entire Korean population. This growing new trend has prompted researchers to become interested in what types of people rely on online social media tools in their interactions with others $[10,18]$. OSN, like Facebook, provides users with a unique CMC environment where individuals can disclose their thoughts, feelings, and experiences within their circle of personal-ties. Having access to the OSNs, however, is different from having access to the content that resides on it [23]. If people lack of motivation, appropriate skills, cognitive ability, and self-confidence assertively use the OSNs, a large portion of them may get left behind socially, economically and politically [19]. The arrival of OSNs population has shown the emergence of a new paradigm of digital divide.

In the beginning, the digital divide was conceptualized as a gap between those who do and those who do not have access to digital technologies. Since growth of social media usage, research on the digital divide is moving beyond physical access to a multifaceted concept of access that involves cognitive access, social access, and differentiated uses of the web. Although this new area has also focused on sociodemographic predictors, it has incorporated other factors that affect the usage, such as social and personality predictors [5].

The Five Factor Model, one of personality traits, which had been used in the management and psychology fields to predict user's attitudes and behavior, begun to examine the of psychological factors individual's use of technology, such as OSNs. The reason for personality predictor is growing dominant factor in OSNs research is OSNs' inherent interpersonal nature and self-disclosure aspects. But [1, 2] argues that many web designers perceive users as a homogeneous group and take no account of personality differences and this results rack of fulfilling individual needs and drives "second-level digital divide".

This research seeks to adopt and implement SASANG Constitution, which is proven to have high reproducibility that brings together physiological and pathological aspects. The purpose of this study is to examine the role of SASANG Constitution in Facebook usage.

\section{Literature Review}

\subsection{Personality Traits and OSNs Uses}

The personality theory considered by many to have the most relevance to the social aspects of the Internet is Five Factor Model [10]. This Big Five framework is model of personality that contains five factor representing personality traits as broad level: extraversion, neuroticism, openness to experiences, agreeableness, and conscientiousness. Each factor is bi-polar (e.g., extraversion vs introversion) and brief description of these traits is [10]:

- Neuroticism reflects a person's tendency to experience psychological distress and high levels of the trait are associated with sensitivity to threat. 
- Extraversion reflects a person's tendency to be sociable and able to experience positive emotions.

- Openness to Experience represents an individual's willingness to consider alternative approaches, be intellectually curious and enjoy artistic pursuits.

- Agreeableness represents aspect of interpersonal behavior, reflecting a tendency to be trusting, sympathetic and cooperative.

- Conscientiousness reflects the degree to which an individual is organized, diligent and scrupulous

Early researches $[1,2]$ of examining personality and internet uses determined introversion and neuroticism were significantly related online activities. [4] concluded that people who are introverts or neurotic because of their difficulties in social interactions will locate "real me" through the internet; and extroverts and low non-neurotic people will locate their "real me" through traditional social interactions. Because it's anonymity of the internet environment at that time would made hypotheses more related to introvert and neurotic.

However after restriction on anonymity in many OSNs, researches have reflected a reversal association between personality and internet uses. Most people use OSNs to interact with people they already know [16]. As such OSNs may be more likely to interact in extravert way.

The meaningful personality traits of FFM that exert influence on OSNs can be sorted into three main traits-, neuroticism, extroversion and openness to experience $[1,2,4]$. In this research, we will only look into neuroticism and extroversion that have a positive correlation with $S A S A N G$ Constitution.

Neuroticism explains emotional stability and anxiety and predicts a person's degree of sensitivity, it is stated that high neuroticism makes use of Internet out of loneliness and emotional instability [1, 2] and that individual depends on the Internet for communication purposes. People who exhibit high on neuroticism tend to spend more time on OSNs than extraverts [1,21] or low level of Neuroticism [3], because they use OSNs to make themselves as attractive as possible [18] on online. Also people who exhibit neurotic tendencies like to use chat rooms [1] and instant messaging [11]. [3] found that highly neurotic people were more likely to post private information on their Facebook profile than those in the less neurotic group because more neurotic people for control over information[6].

Extraversion refers to the extent to which individuals are social, cheerful, optimistic, active and talkative. Individuals high in extraversion are expected to engage in high amounts of social interaction and approach others more easily [18]. [3] reported extraverts engaging in less divulgence of personal information on their Facebook profiles. These findings suggest that extraversion is more closely related to personal disclosure of one's current activities and thoughts as opposed to established interests, favorites and relationship status. A person with a strong tendency toward introversion possesses weaker self-regard and prefers to express individual true identity on line, whereas extroverts would prefer to express individual true identity in an off-line environment [1, 11]. [3] suggested that extraverts would see social networks as places to share information and opinions rather than as a substitute for real interaction. Studies 
also claim that introverted people with high levels of neuroticism document personal information more accurately $[1,13]$.

\subsection{SASANG Constitution}

According to SASANG Constitutional Theory, the individual differences in behavioral patterns, nature, physical characteristics, and susceptibility to certain diseases are based on people's bio-psychological traits. Despite its potential value in constructing personalized and integrative medicine, traits of SASANG types have not been studied in a quantitative and scientific manner, barring their development and propagation to other countries and cultures [8].

SASANG Constitution was systematically theorized in the book Dong-Yi-Soo-BoWon (The Principle of Life Preservation in Oriental Medicine) [17] by Jae Ma Lee in the field of traditional Korean Medicine. In SASANG Constitution, humans are classified into four SASANG types; Tae-Yang (TY), So-Yang (SY), Tae-Eum (TE), and SoEum (SE). Each type has unique characteristics, as explained below [24].

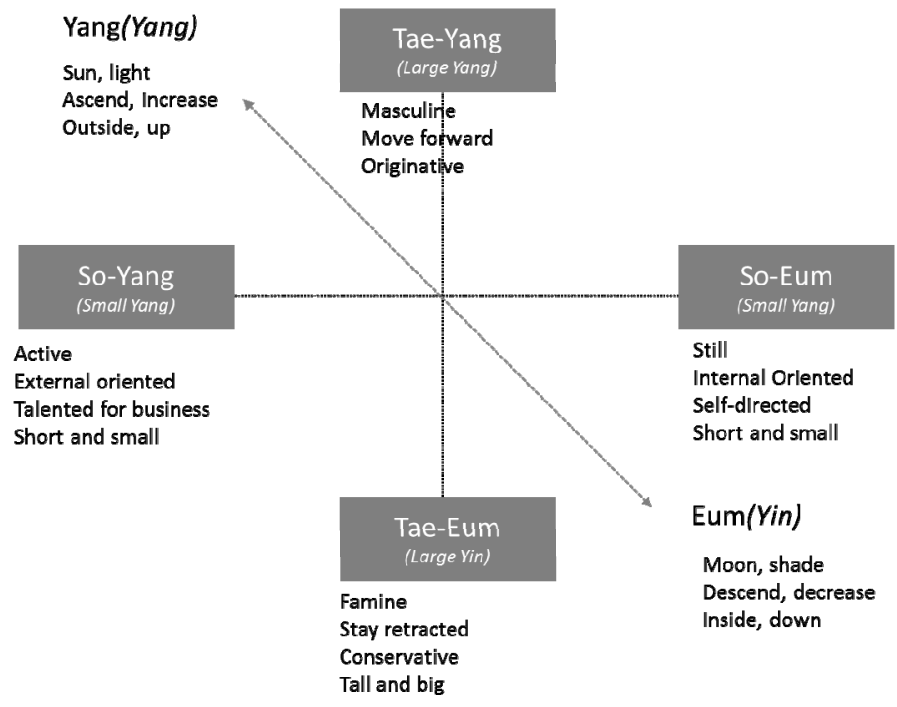

Fig. 1. SASANG Constitution

- T'ae-Yang (TY) types have large lungs and a small liver. They are usually creative, genuine, and visionary people who have good judgment, strong ambition, and charismatic leadership. Statistically, this type is quite rare (about $0.05 \%$ in population).

- T'ae-Eum (TE) types have large livers and small lungs. The personality is conservative and cautious, not outgoing, but reticent, quiet, in general. This type exhibits perseverant and outstanding leadership, and it has the largest portion among four types (about 50\%). 
- So-Yang (SY) types have large spleens and small kidneys. They tend to be extroverts and progressive. This type is also passionate and inquisitive (about 30\%).

- So-Eum (SE) types are generally short and small, and they usually have large kidneys and a small spleen. Their personality is generally adorable, obedient, kind, prudent, and inactive (about 20\%).

For the purpose of categorizing $S A S A N G$ Constitution with Facebook users, the correlation between $S A S A N G$ Constitution, neuroticism and extroversion are summarized through the literature review as below $[8,9]$.

Table 1. SASANG Constitution and Personlaity Traits(FFM)

\begin{tabular}{c|cl}
\hline & Extroversion & Introversion \\
\hline High Neuroticism & Tea-Yang (TY) & So-Eum (SE) \\
Low Neuroticism & So-Yang (SY) & Tea-Yin (TE) \\
\hline
\end{tabular}

\subsection{Research Hypothesis}

Based on the literature review, the following research hypothesis can be posited.

H1. The frequency of Facebook usage time for So-Eum (SE) and So-Yang (SY) will differ as they are opposite to each other.

H2. So-Eum (SE), unlike other physiological types, will utilize Facebook to express his/her emotions and identity.

H3. So-Eum (SE), compared to other physiological types, will document personal information accurately and in large quantities.

\section{Experiment}

\subsection{Subjects}

Surveys were conducted on 102 personnel who were a researcher's Facebook friends, which allows for the subjects and the contents of their profiles to be inspected. The sample was comprised of 60 men and 42 women, having an average age of 29.12 years $(\mathrm{SD}=5.81)$. An online survey was conducted on a Facebook page for the duration of 20 days (Aug, 1 - 20, 2012). To identify Facebook users' SASANG Constitution, QSCC II was distributed and results were collected through email.

\subsection{Measures}

QSCCII (Questionnaire for SASANG Constitution Classification II) is a SASANG Constitution-based inventory, which was developed by the Department of SASANG Medicine at Kyung Hee Medical Center (Seoul, Korea) in 1993. It has been also validated using 265 subjects from the Department of SASANG Constitutional 
Medicine or Oriental Medicine \& Western Medicine Cooperative Health Examination Center, Kyung Hee University Medical Center. The QSCC is composed of 121 forced-choice items. The internal consistency (Cronbach's alpha) of this inventory was $0.57,0.59$ and 0.63 for the SY, TE and SE types, respectively [4]. The SASANG Constitution of an individual was determined following two procedures. SASANG type was determined using PC-based software.

\subsection{Facebook Questionnaire}

The online Facebook Questionnaire was a 10-item questionnaire which was designed to measure basic Facebook use, motives of use and personal information posting on Facebook profile. Basic use items were designed to collect information about the use of common functions on Facebook, such as time spent using Facebook, frequency of visit, time spent on site and number of Facebook friends. From the previous research 6 items (social and contents investigation, communication, social connection, content gratification, self-expression or self-disclosure and social surfing) were used to assess the different motives towards Facebook. Participants were also asked to indicate what categories of personal information they had posted on their profiles. Response formats on this tool ranged from dichotomous item to five-point rating scales with a number of items requiring a numeric response.

\section{$4 \quad$ Results}

To determine whether Facebook usage time differs by physiological type, crosstabulation was used. Table 2 below demonstrates that $41.7 \%$ of So-Eum (SE) users were into the Facebook for more than an hour per day, scoring the highest.

Table 2. Facebook Time Spend

\begin{tabular}{c|ccc}
\hline Time Spend & TE $(\%)$ & $S Y(\%)$ & $S E(\%)$ \\
\hline Less than 30 min & 29.4 & 36.4 & 33.3 \\
30min to 1hour & 47.1 & 36.4 & 25.0 \\
1hour to 2hours & 17.6 & 9.1 & 16.7 \\
2hours to 3hours & 5.9 & 9.1 & 8.3 \\
More than 3hours & 0.0 & 9.1 & 16.7 \\
\hline
\end{tabular}

As the Table 3 indicates, when looking at the frequency of site access, So-Eum (SE) scored the least in the category of 'less than five times', while scoring the highest in the category of 'almost continuously'. From this, we can interpret that, compared with So-Eum (SE), So-Yang (SY) spares less time for Facebook, hence validating Hypothesis 1. 
Table 3. Frequecy of Facebook access

\begin{tabular}{c|ccc}
\hline Frequency & TE $(\%)$ & $S Y(\%)$ & $S E(\%)$ \\
\hline Less than 5 times & 35.3 & 36.4 & 25.0 \\
5 to 10 times & 35.3 & 22.7 & 33.3 \\
10 to 15 times & 5.9 & 22.7 & 8.3 \\
15 to 20 times & 17.6 & 18.2 & 8.3 \\
Almost continuously & 5.9 & 0.0 & 25.0 \\
\hline
\end{tabular}

The second hypothesis aims to identify the differing purposes for using Facebook by physiological type. For analysis, we used ANOVA with 0.05 measure point. As Table 4 below suggests, Tae-Eum (TE) and So-Eum (SE) stated that they use Facebook to express themselves, but So-Yang (SY) scored less in that category ( $\mathrm{p}=$ 0.009). This validates the claim that Tae-Eum (TE) and So-Eum (SE) with higher neuroticism make use of Facebook to express their emotional states and situations.

Table 4. Motivation of Facebook use

\begin{tabular}{|c|c|c|c|}
\hline Time Spend & $\begin{array}{c}T E \\
\text { (average value) }\end{array}$ & $\begin{array}{c}S Y \\
\text { (average value) } \\
\end{array}$ & $\begin{array}{c}S E \\
\text { (average value) }\end{array}$ \\
\hline Social Investigation & 1.76 & 1.95 & 1.5 \\
\hline Communication ${ }^{*}$ & 4.11 & 3.59 & 4.25 \\
\hline Social Connection & 3.94 & 3.81 & 4.0 \\
\hline Contents Gratification & 2.47 & 2.36 & 2.33 \\
\hline Self-Expression/Disclosure ${ }^{* * *}$ & 3.29 & 2.22 & 3.41 \\
\hline To hang out* & 3.29 & 2.68 & 3,33 \\
\hline
\end{tabular}

The Third Hypothesis aimed to determine whether there are differences in terms of filling in Facebook profile categories according to SASANG Constitution. Except for the 'living in' category, So-Eum (SE) scored the highest for filling in and writing most of the profile categories.

Table 5. Facebook Profile List

\begin{tabular}{c|ccc}
\hline Profile List & $T E(\%)$ & $S Y(\%)$ & $S E(\%)$ \\
\hline About you & 61.1 & 52.6 & 75.0 \\
Basic Info & 94.4 & 84.2 & 100.0 \\
Contact Info & 44.4 & 42.1 & 66.7 \\
Living & 66.7 & 31.6 & 58.3 \\
Work \& Education & 33.3 & 52.6 & 75.0 \\
Favorite Quotation & 22.2 & 21.1 & 25.0 \\
ETC & 0.0 & 10.5 & 0.0 \\
\hline
\end{tabular}




\section{Conclusion}

This research focused on analyzing OSN usage patterns as seen through user's personality factors. It sought to verify the hypotheses that were proposed to assess the correlation between SASANG Constitution and personality factors. From the critical literature review, three hypotheses were established, and after a survey the following conclusions were drawn.

1. So-Eum (SE), in comparison to its counterpart So-Yang (SY) who possesses more emotional stability, had less of Facebook usage time and frequency.

2. The introverted So-Eum (SE) with high neuroticism placed more meaning on expression of oneself in their usage of the Facebook.

3. The introverted So-Eum with high neuroticism documented their personal information with higher accuracy.

Realizing the limitations of this research, future research will take the following forms. First, the difference in usage of Facebook by SASANG type will spill over into looking not just at the Facebook but OSNs' other functions as well. For instance, interface design factors will be arranged in detail to suggest a design guideline and experiments for different physiological types.

This research was the first attempt in Korea to explore SASANG Constitution and OSN users' Constitution, thus had its innate research limits. Yet, nonetheless, it sheds light into the untapped area of researching a design as seen through OSN user's Constitution.

\section{References}

1. Amichai-Hamburger, Y., Ben-Artzi, E.: Loneliness and Internet use. Computers in Human Behavior 19(1), 71-80 (2003)

2. Amichai-Hamburger, Y., Vinitzky, G.: Social network use and personality. Computers in Human Behavior 26, 1289-1295 (2010)

3. Amiel, T., Sargent, S.: Individual differences in Internet usage motives. Computers in Human Behavior 20(6), 711-726 (2004)

4. Bargh, J.A., McKenna, K.Y.A.: Can you see the "real me"? A theory of relationship formation on the Internet. Journal of Social Issues 58(1), 33-48 (2002)

5. Boyd, D., Heer, J.: Profiles as conversation: Networked identity performance on Friendster. In: Proceedings of theThirty-Ninth Hawai'i International Conference on System Sciences. IEEE Press, Los Alamitos (2006)

6. Butt, S., Phillips, J.: Personality and self-reported mobile phone use. Computers in Human Behavior 24(2), 346-360 (2008)

7. Chae, H., Lyoo, I.K., Lee, S.J., Cho, S., Bae: An alternative way to individualized medicine: psychological and physical traits of Sasang typology. The Journal of Alternative and Complementary Medicine 9(4), 519-528 (2003)

8. Chae, H., Park, S.H., Lee, S.J., Kim, M.G., Wedding, D., Kwon, Y.K.: Psychological profile of SASANG Constitution: a systematic review. Evidence Based Complement Alternative Medicine (2009) 
9. Chae, H., Park, S.H., Lee, S.J.: Hippocrates, Eysenck and the SASANG typology. European Psychiatry 26(1), 1013-1023 (2011)

10. Correa, T., Hinsley, A.W., Zuniga, H.: Who Interacts on Web?: The intersection of user's personality and socialmedia use. Computers in Human Behavior 26, 247-253 (2010)

11. Ehrenberg, A., Juckes, S., White, K.M., Walsh, S.P.: Personality and self-esteem as predictors of young people's technology use. Cyber-Psychology \& Behavior 11(6), 739-741 (2008)

12. Ellison, N.B., Steinfeld, C., Lampe, C.: The benefits of Facebook "Friends:" Social capital and college students' use of online social network sites. Journal of Computer-Mediated Communication (2007)

13. Gross, R., Acquisti, A.: Information revelation and privacy in online social networks (The Facebook case). In: Proceedings of ACM Workshop on Privacy in the Electronic Society, pp. 71-80 (2005)

14. Hargittai, E.: Whose space? Differences among users and non-users of social network sites. Journal of Computer-Mediated Communication 13(1), article 14 (2007), http: //jcmc.indiana. edu/vol13/issue1/hargittai.html

15. Kim, S., Ko, B., Song, I.: A study on the standardization of QSCC (Questionnaire for the SASANG Constitution Classification). J. Korean Orient. Med. Soc. 17, 337-393 (1996)

16. Lampe, C., Ellison, N., Steinfield, C.: The benefits of Facebook "friends": Social capital and college students' use of online social network sites. Journal of Computer-Mediated Communication 12(4), 1143-1168 (2007)

17. Lee, J.M.: Dong-Yi-Soo-Se-Bo-Won. Lee Jae Ma, Seoul, Korea (1894)

18. Moore, K., McElroy, J.C.: The influence of personality on Facebook usage, wall postings, and regret. Computers in Human Behavior 38(10), 267-274 (2012)

19. Newhagen, J.N., Bucy, E.P.: Routes to media access. In: Newhagen, J.N., Bucy, E.P. (eds.) Media Access: Social and Psychological Dimensions of New Technology Use. Lawrence Erlbaum Associates, Mahwah (2004)

20. Sheldon, P.: Student favorite: Facebook and motives for its use. Southwestern Mass Communication Journal 23(2), 39-53 (2008)

21. Tidwell, L.C., Walther, J.B.: Computer-mediated communication effects on disclosure, impressions, and interpersonal evaluations: Getting to know one another a bit at a time. Human Communication Research 28(3), 317-348 (2002)

22. Ross, C., Orr, E.S., Sisic, M., Arseneault, J.M., Simmering, M.G., Orr, R.R.: Personality and motivations associated with Facebook use. Computers in Human Behavior 25(2), 578586 (2009)

23. Van Dijk, J.: Divides in succession: Possession, skills, and use of new media for social participation. In: Media Access: Social and Psychological Dimensions of New Technology Use, pp. 233-254. Lawrence Erlbaum Associates, Mahwah (2004)

24. The Association of Korean Oriental Medicine official Site, http: / /www. akom.org/eng/theory/tI12.html 